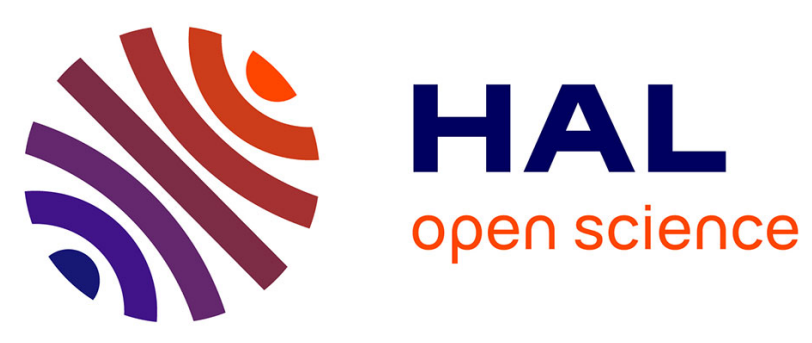

\title{
Documenting carved stones by 3D modelling - Example of Mongolian deer stones
}

\author{
Fabrice Monna, Yury Esin, Jérôme Magail, Ludovic Granjon, Nicolas Navarro, \\ Josef Wilczek, Laure Saligny, Sébastien Couette, Anthony Dumontet, Carmela \\ Chateau Smith
}

\section{To cite this version:}

Fabrice Monna, Yury Esin, Jérôme Magail, Ludovic Granjon, Nicolas Navarro, et al.. Documenting carved stones by 3D modelling - Example of Mongolian deer stones. Journal of Cultural Heritage, 2018, 34 (November-December), pp.116-128. 10.1016/j.culher.2018.04.021 . halshs-01916706

\section{HAL Id: halshs-01916706 \\ https://shs.hal.science/halshs-01916706}

Submitted on 22 Jul 2019

HAL is a multi-disciplinary open access archive for the deposit and dissemination of scientific research documents, whether they are published or not. The documents may come from teaching and research institutions in France or abroad, or from public or private research centers.
L'archive ouverte pluridisciplinaire HAL, est destinée au dépôt et à la diffusion de documents scientifiques de niveau recherche, publiés ou non, émanant des établissements d'enseignement et de recherche français ou étrangers, des laboratoires publics ou privés. 
See discussions, stats, and author profiles for this publication at: https://www.researchgate.net/publication/328759923

\section{Documenting carved stones by 3D modelling-Example of Mongolian deer} stones

Article in Journal of Cultural Heritage · May 2018

Dol: 10.1016/j.culher.2018.04.02

CITATIONS

10 authors, including:

Fabrice Monna

University of Burgundy

121 PUBLICATIONS 2,594 CITATIONS

SEE PROFILE

Jérôme Magail

Museum of Prehistoric Anthropology of Monaco

26 PUBLICATIONS 21 CITATIONS

SEE PROFILE
303

Yury Esin

Khakassian Research Institute for Language, Literature, and History 10 PUBLICATIONS 12 CITATIONS

SEE PROFILE

Ludovic Granjon

French National Centre for Scientific Research

20 PUBLICATIONS 5 CitATIONS

SEE PROFILE

Some of the authors of this publication are also working on these related projects:

Impact of ancient mining and smelting activities on present terrestrial and aquatic ecosystems View project

ANR CARE View project 


\title{
Documenting carved stones by 3D modelling - Example of Mongolian deer stones
}

\author{
Fabrice Monna ${ }^{\mathrm{a}, *}$, Yury Esin $^{\mathrm{b}}$, Jérome Magail ${ }^{\mathrm{c}}$, Ludovic Granjon ${ }^{\mathrm{d}}$, Nicolas Navarro ${ }^{\mathrm{e}, \mathrm{f}}$, \\ Josef Wilczek $^{\mathrm{a}, \mathrm{g}}$, Laure Saligny ${ }^{\mathrm{d}}$, Sébastien Couette ${ }^{\mathrm{e}, \mathrm{f}}$, Anthony Dumontet ${ }^{\mathrm{a}}$, \\ Carmela Chateau ${ }^{\text {h }}$ \\ a ARTEHIS, UMR CNRS 6298, université de Bourgogne-Franche Comté, 6 Boulevard Gabriel, Bat. Gabriel, 21000 Dijon, France \\ ${ }^{\mathrm{b}}$ Khakassian Research Institute for Language, Literature and History, 23, Shchetinkin Street, 655017 Abakan, Republic of Khakassia, Russia \\ ${ }^{\mathrm{c}}$ Musée d'anthropologie préhistorique de Monaco, 56, boulevard du Jardin exotique, 98000 MC, Monaco \\ ${ }^{\mathrm{d}}$ MSH de Dijon, USR CNRS 3516, université Bourgogne Franche-Comté, 6, esplanade Erasme, 21066 Dijon, France \\ e EPHE, PSL Research University, 21000 Dijon, France \\ ${ }^{\mathrm{f}}$ Biogéosciences UMR CNRS 6282, université Bourgogne Franche-Comté, 6, boulevard Gabriel, 21000 Dijon, France \\ g Ústav archeologie a muzeologie, Masarykova univerzita, Arna Nováka 1, 60200 Brno, Czech Republic \\ h Université de Bourgogne, UFR SVTE, 6, boulevard Gabriel, 21000 Dijon, France
}

\section{A R T I C L E I N F O}

\section{Article history:}

Received 15 October 2017

Accepted 20 April 2018

Available online 4 May 2018

\section{Keywords:}

Archaeology

Rock art

Mongolia

Late Bronze Age

Positive openness

Photogrammetry

Documentation

Recording methods

\begin{abstract}
A B S T R A C T
Rock art studies are facing major technical challenges for extensive documentation. Nowadays, recording is essentially obtained from time-consuming tracing and rubbing, techniques that also require a high level of expertise. Recent advances in 3D modelling of natural objects and computational treatment of the modelled surfaces may provide an alternative, and reduce the current documentation bottleneck. The aim of this study is to examine the extent to which such treatments can be applied. The case study presented here concerns the famous deer stones erected by ancient Mongolian nomad populations. The 3D acquisition workflow is based on structure-from-motion, a versatile photogrammetric technique, well adapted to various field conditions. From the 3D geometry of objects of interest, elevation raster maps are produced by projection on four sides of the stela. These digital elevation models are then tested using algorithms based on differential geometry, sky visibility and local morphology, the general principles of which are briefly exposed. All these approaches may be appropriate with essentially planar surfaces. However, in the case of irregular carved surfaces, such as those of deer stones, the most efficient algorithm appears to be positive openness. In favourable cases, the incisions can be automatically delineated, facilitating the final drawing. Results obtained at the end of the process are comparable to the best drawings available in the literature, and can also include archaeological information about rock surface conditions. The procedure considerably accelerates the workflow in comparison with traditional techniques, reduces the level of expertise required, and provides 3D models, which can easily be shared, or further analysed by morphometric methods, for instance.
\end{abstract}

(C) 2018 Elsevier Masson SAS. All rights reserved.

\section{Introduction}

There is an urgent need to document the huge amount of carved rock art still present around the world. Nowadays, this cultural heritage is jeopardised by human degradation related to mass tourism, developmental progress, such as road and infrastructure building, dams, ore mining, etc. [1], or worse, by plundering, intentionally organised for illicit art traffic [2]. Climate change can also drastically

\footnotetext{
* Corresponding author.

E-mail address: Fabrice.Monna@u-bourgogne.fr (F. Monna).
}

accelerate its fading [3]. Even though these immediate threats do not weigh on all rock art, its documentation is essential for studying the symbolism of the figures, their spatial organisation, and their stylistic variations through time and space [4,5]. The diversity of shapes represented may be such that working with the most exhaustive inventory is essential for the better understanding of past societies, which invested considerable time and effort to leave a testimony of their conception of the world, their occupations, and beliefs. That is why delineating contours of symbols from 2D documentation and preparing them (e.g. by skeletonization [6]) for further classification with an automatic process is an active field of research $[7,8]$. 
One of the most widespread rock art recording techniques worldwide is tracing on a transparent sheet, pressed closely against the carved surface (for examples concerning Mongolian rock art, see $[9,10])$. Although quite convenient for a skilled archaeologist in the simplest cases, this technique suffers from some major drawbacks. First, it is geometrically impossible to adequately fit a plane transparent sheet to an irregular $3 \mathrm{D}$ surface. The resulting tracing at the $1: 1$ scale must be scanned or photographed, perhaps in sections, depending on its total size, and reassembled before reworking with a vector graphics editor. The entire process is extremely timeconsuming, especially in the field, and may lead to distortions, tedious to handle at the final step, which is expected to correspond to a true-to-life orthographic view of the carved surface. Such techniques require a very high level of training and expertise from the operator. Another major weakness is that the 3D geometry of the carved parts is poorly captured. Yet, this geometry contains information vital for the in-depth study of carving techniques, for clustering figures based on their technical similarities, and possibly for the establishment of chronological relationships, as shown by [11]. Although photography may palliate some of these issues (note however that photography always suffers from perspective distortion), it may often be inadequate to clearly distinguish carved areas. The crystallographic texture and colour of the stone surface may be heterogeneous, presenting little contrast with the carved parts. Vegetation, such as thin crustose lichens, may grow on the substrate, masking figures. Under normal (axial) light, there may be insufficient shadow to emphasize the relief. High incident angles are generally sought; either in natural conditions by selecting the best time for photography (e.g. before sunset for horizontal surfaces), or using properly positioned artificial lights with sophisticated procedures [12,13]. Capture is generally undertaken by night, or under a shelter; both solutions considerably reduce acquisition capacity. Rubbing with special paper, which is then photographed, can reveal many poorly visible, or even invisible, carved details on the stone surface, regardless of lighting. This is a serious advantage by comparison with simply tracing on a transparent sheet, or photography, but the technique requires additional skills. Both tracing and rubbing necessarily imply physical contact, which can potentially damage the surface [14], so that special agreement from competent authorities may be required. In any case, photography alone is unable to capture 3D geometry, without further processing.

Over the last three decades, there has been a technological revolution in computer vision for 3D acquisition and its application to real-world objects [15-21], coeval with major advances in mathematical treatment [22-24]. Such advances could well be advantageously applied to extensive rock art documentation. Noncontact 3D scanners based on either structured light or laser beam $[25,26]$ are costly and better adapted to objects smaller than $1 \mathrm{~m}$. They need electric power, calibration and computer control, and they do not operate well under direct sunlight. Although they have been used successfully for rock art acquisition [27], they are probably not best adapted for outdoor fieldwork. In contrast, structure-from-motion (SfM), together with dense point cloud modelling, is a highly versatile, inexpensive, mature photogrammetric technique, increasingly applied in archaeology [16,28-30]. Scene geometry, camera positions and orientations are reconstructed simultaneously by iteratively matching a set of features, automatically identified in multiple overlapping images taken from different points of view [31]. With a set of several dozen pictures captured in only a few minutes, a complex scene can be modelled at extremely high resolution depending, among other things, on the size of the camera sensor, the focal length of the lens, and the distance between the camera and the object of interest [32]. Once the geometry has been reconstructed, the 3D model must be treated to identify the carved areas, see e.g. [29]. Algorithms from the field of geospatial techniques [33], used to highlight topographic shapes, such as peaks, valleys and slopes, can identify carved areas as depressions on the landscape of the stone surface. The aim of the present study is to evaluate the ability of these algorithms to produce accurate 2D documentation of carved stones, as close as possible to a ready-to-print state, or at least requiring minimum work to attain the current standards for publication in archaeology. It is necessary to explain the principles involved, as well as the importance of the correct setting parameters, because basic understanding of the available approaches is fundamental before selecting the optimal method for a given situation. Three different families of algorithms are tested here. They are based on differential geometry, sky visibility, and local morphology. The real-life objects used as a case study are decorated stelae belonging to the "Khereksuurs and Deer Stones Culture", which were erected in the Eurasian steppe belt at the end of the 2nd to early 1st millennium BC. These megaliths, $0.5-5 \mathrm{~m}$ tall, were hand-carved with elegant symbols, the most emblematic of which is a deer. Stelae studied in this article belong to sites in the Khoid Tamir valley and Uushgiin Uvur; a site registered on the world heritage tentative list (http://www.whc.unesco.org/en/tentativelists/5953/). The 3D acquisition in the field, as well as the 3D model treatments, are described in detail to provide a pipeline for the reader. Importantly, the time required for each approach (3D modelling and expert rubbing used as reference) is evaluated. The outcomes are qualitatively and quantitatively compared to assess their suitability for extensive rock art documentation.

\section{Material and methods}

\subsection{Corpus}

Among all monuments dating from the Bronze Age found in Mongolia, the most famous are the deer stones, thus named because they depict deer, generally moving along a helical path, whirling into the sky, or following a vertical linear movement on each side [34]. Their legs are folded under their bellies, their bodies are stretched, extended by a beak-like muzzle. Other animals, belts, earrings and necklaces, weapons and tools, shields, and also the sun and moon can be found on these stelae [35-38]. The organisation of these symbols represents an exceptional synthesis of the nomad's thoughts. Often made of granite or sandstone, these stones are found in association with funeral and memorial complexes. They are believed to represent ideas of funeral practices and sacrificial rituals, helping the departed warrior's or leader's soul to reach what lies beyond death [39]. The photogrammetric campaign, undertaken in July 2015, within the framework of the "Monaco-Mongolian Joint Archaeological Mission", focussed on the site of Tsatsiin Ereg in the Khoid Tamir valley, located about $500 \mathrm{~km}$ southwest of Ulaanbaatar [40]. This site contains numerous tumuli, barrows, stones arranged in quadrangles, circles, or alignment, and more than 100 stelae, forming archaeological complexes [10]. The other targeted site is Uushgiin Uvur located near the town of Moron. In the following, three examples are presented: two stelae from Tsatsiin Ereg (stelae No. 35 and 36) and one from Uushgiin Uvur (S7). They were chosen because they differ in terms of carving depth, surface preservation, and more generally, in ease of reading.

\subsection{Photogrammetric workflow}

\subsubsection{Capturing the scene}

This task consists in capturing a set of overlapping pictures (70-80\%), containing at least three times all points belonging to the $3 \mathrm{D}$ geometry of the objects of interest. Two different cameras were used at that step, depending on the size of the objects. Small stelae 
were photographed by a hand-held NIKON D800 semi-pro fullframe DSLR (sensor $24 \times 36 \mathrm{~mm}^{2}, 36 \mathrm{Mpix}$ ), equipped with NIKKOR $24 \mathrm{~mm}$ or $50 \mathrm{~mm}$ prime lenses, because both lenses produce very sharp images (Fig. 1a). For stelae taller than $1.5 \mathrm{~m}$, a consumergrade compact SONY DSC-RX100 MIII (sensor $13.2 \times 8.8 \mathrm{~mm}^{2}, 20$ Mpix), $24-70 \mathrm{~mm}$ in $24 \times 36$ equivalent, was used with the focal set at $24 \mathrm{~mm}$. For the top of the stela, the camera was mounted on a 4-m-long telescopic pole (Rode boompole) and controlled by WiFi using a Samsung Galaxy tablet, fixed on the pole. Aperture was maintained at $f / 8-11$ to ensure sharpness over the whole picture, i.e. adequate depth of field, and sufficient speed to avoid the use of a tripod or blurring through camera shake. To scale the final model in metre units, the shots included a self-retracting metallic measuring tape, open at 1 metre, positioned at the foot of the stela (Fig. 1a). Photographs were taken whenever possible under a cloudy or overcast sky. Clouds act as light diffusers, producing soft lighting, which reduces shadows. Such light conditions greatly facilitate 3D model reconstruction of carved areas, as they appear sharp and detailed, unlike traditional archaeological photography, which seeks strong shading in incisions [41]. Care was taken to avoid capturing moving features inside the scene during the photo session, such as people or moving shadows. It is difficult to provide definitive guidelines on the minimum number of pictures required, because it greatly depends on the geometry of the object targeted. Multiplying the number of shots from different angles is generally recommended, as it will increase the number of matching features and redundancy [31]. One must however keep in mind that computing time during the modelling step rises dramatically with the number of pictures processed. Depending on the size of the stelae, pictures were taken at a distance varying from 2 to $5 \mathrm{~m}$ that produces an object sampling distance of $0.3-0.6 \mathrm{~mm}$ per pixel. Only $25-50$ pictures were necessary to adequately cover the deer stones, because of their rather simple, mostly convex geometry (Fig. 1a).

\subsubsection{D model production}

Several free solutions are currently available: e.g. Micmac (http://www.logiciels.ign.fr/?Micmac), Visual SFM [42], dense reconstruction from multiview stereo algorithms [43,44] or Meshlab (http://www.meshlab.sourceforge.net/) for meshing. Nonetheless, a commercial solution, PhotoScan (http://www.agisoft.com/), was preferred for this study, as it covers the entire 3D reconstruction workflow in a user-friendly form. The principles of the process, only described briefly below, can easily be found in more detailed form elsewhere $[45,46]$. Because wide-angle view produces significant distortion on the edges of the image, lens calibration is required. This can be precisely determined in the laboratory for each camera, or automatically set by photogrammetric bundle adjustment, which also estimates camera positions and orientations [26]. Once the pictures have been aligned, a sparse point cloud is produced. This point cloud is densified, and a triangular mesh model is generated. The original colour is obtained from the pictures combined into a texture map, which is wrapped on to the object (Fig. 1a). While picture acquisition typically takes 5-15 min per stela in the field, the complete reconstruction of the $3 \mathrm{D}$ scene may take $3-5 \mathrm{~h}$ in the laboratory. A high-end consumer grade computer was used: i7 5960x, 8 cores, equipped with 64 Go of RAM, and two 4 Go-RAM NVIDIA GeForce GTX 980 mounted in SLI. Typically, the final dense cloud is composed of more than 30 million points, and the 3D model contains more than 4 million faces.

\subsubsection{Digital elevation models and orthomosaics}

With the structure-from-motion technique, the 3D models are produced without scale, so that they must be scaled manually using the two ends of the measuring tape laid out at the foot of the stela for this purpose (Fig. 1a). In the following, a rectangular bounding box of the stela is considered. Its orientation is set manually in PhotoScan by considering the natural deer stone position on the ground (see Fig. 1a). Four digital elevation models (DEMs) are produced by planar projection on each of the four vertical sides of this bounding box. Such rasterization converts the distance of the scene to the plane targeted into an image containing a dense array of values (also called a $2.5 \mathrm{D}$ grid), which can be saved in raster format. Although extremely high resolution can be reached by structure-from-motion, depending on the camera resolution, the focal, and the distance from the shooting position to the scene, the DEM resolution was limited in the following to $1 \mathrm{~mm}$ per pixel, which is sufficient to extract the geometry of the carved areas, at least in our case, while maintaining the definition of DEM images at a reasonable level for further calculation. Similarly to DEMs, orthomosaics are systematically produced for each of the four vertical faces, this time in full resolution, for archival purposes (Fig. 1b). (a)

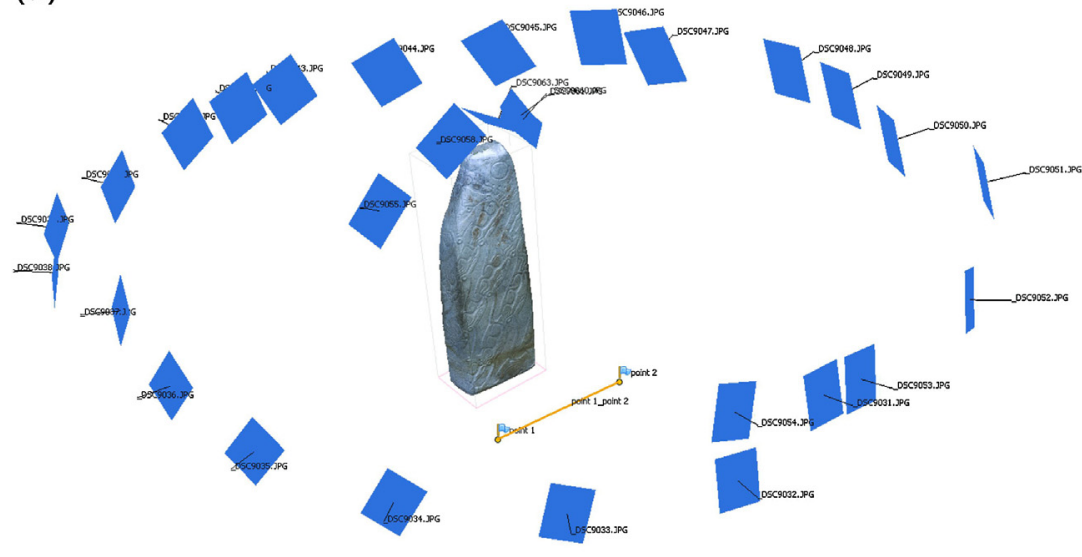

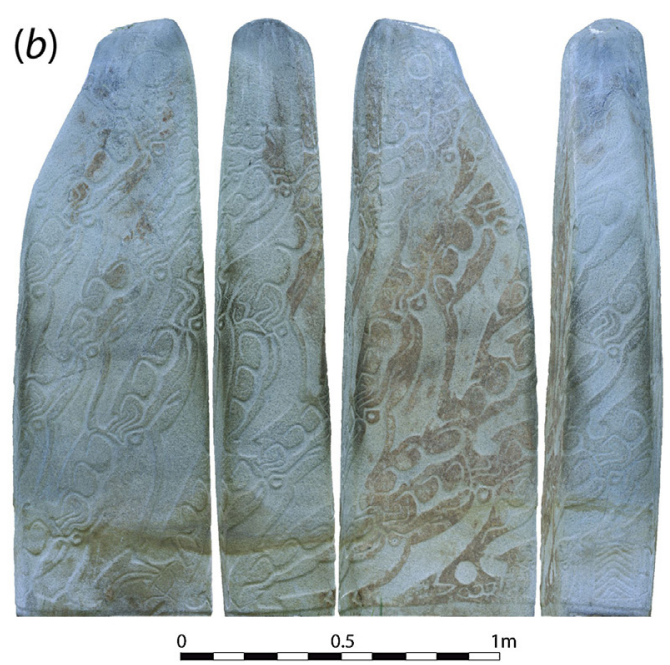

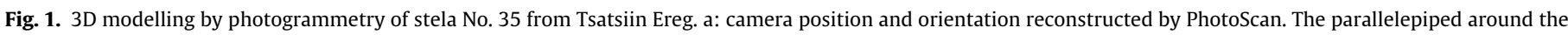

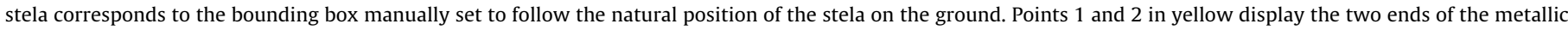
measuring tape used for scaling; b: orthomosaics of the four main sides of the stela. 


\section{The algorithms tested}

\subsection{Underlying idea of using geospatial and terrain analysis}

The methodology proposed here aims at evaluating, and possibly taking advantage of, some of the numerous algorithms used in remote-sensing, more particularly those using high-resolution topographic data (like LiDAR data) to identify, from DEMs, specific features in landscapes, such as valleys, ridges, peaks, pits, or anomalies related to archaeological sites [47-50]. In the following, carved stone surfaces are viewed as landscapes, and carved areas as small-scale valleys, bordered by slopes and crests. One of the simplest tools, the commonly used analytical hill-shading, which simulates artificial illumination on the DEM surface, is based on the same principle as the use of an oblique light source to highlight incisions in classic photography [51]. However, hole depth cannot be recognised, nor can any linear anomalies lying parallel to the light beam [52]. Even though multiple virtual light sources are considered to palliate these drawbacks, this procedure is better adapted to sharp reliefs, which is not the case here [52]. For these reasons, other families of algorithms, which can be divided into three main groups, are tested here. They are listed below, and their principles briefly described.

\subsection{Differential geometry-based algorithms}

\subsubsection{Slope and curvature}

The slope angle is defined as the maximum rate of change in elevation between each cell and its neighbours, also known as maximum downhill gradient [24]. It is obtained from the first derivative of the DEM (Fig. $2 a$ and b). The profile curvature is the second derivative of the DEM in a direction parallel to the maximum slope, i.e. the slope of the slope [53]. It varies between positive values for convex and negative for concave shapes, while a zero value denotes a planar surface, steep or horizontal (cf. Fig. 2c). High slope values are expected along the slope of the incised part, while positive curvatures should identify rims, and negative curvatures indicate footslopes. Both slope and curvature depend on the resolution of the DEM, and can be dramatically impacted by the presence of noise blurring the signal, so that prior smoothing may be required. In our case, a circular window of $1 \mathrm{~cm}$ radius (compatible with the targeted features) was used to fit by least squares the surface of interest by quadratic parameters prior to calculation. This operation was performed with SAGA GIS (http://www.saga-gis.org/en/index.html), but these quite common algorithms are available in all GIS software.

\subsubsection{Trend removal approaches}

Removing trend is a common technique to enhance the smallscale positive and negative anomalies in a DEM [50,54]. The simplest way consists in using a low-pass filter, possibly based on mean or Gaussian functions, and to subtract it from the initial DEM. An essential parameter is the kernel size used for smoothing. If it is too small, the residuals do not retain the local features of the surface (red curve in Fig. $2 \mathrm{~d}$ and e); if it is too large, the DEM is over-smoothed and unwanted anomalies appear (blue curve in Fig. 2d and e). Hesse et al. (2010) [48] modified this basic algorithm by introducing the Local Relief Model, abbreviated as LRM. The first step is the same as that described above for trend removal. The intersection of the original and the smoothed DEMs provides a zero contour map, processed to furnish a purged DEM, which is then subtracted from the original DEM. The LRM algorithm is implemented as an add-on of the free GRASS software (https://www.grass.osgeo.org/) and the LiDAR Toolbox software-LiVT (https://www.sourceforge.net/projects/livt/).

\subsection{Visibility-based algorithms}

\subsubsection{Sky-view factor}

This is a widely used alternative method of hill-shading to detect archaeological features from LiDAR raster data [52]. It measures the portion of the hemispheric sky limited by reliefs, seen from a given point [55], and can be deduced from DEMs for each cell, and within a certain radius [56]. Practically, the sky-view factor, SVF, is computed by discretizing the space in $n$ compass directions, and seeking the vertical angle starting from the horizon from which the sky becomes visible, $\gamma_{\mathrm{i}}$ (Fig. $2 \mathrm{f}$ ):

$S V F=1-\frac{\sum_{i=1}^{n} \sin \gamma_{i}}{n}$

Typically $n=8$ sectors are sufficient to extract features of interest, while maintaining computation time at a reasonable level. The maximum search radius must be set by considering the size of the features to be highlighted, as it can either enhance the main structures for high values, or their details (as well as noise) when the radius decreases. Sky-view factor values close to 1 indicate maximum sky visibility, obtained with convex parts and horizontal surfaces, while SVF values close to 0 indicate concave parts, such as valleys, or carved incisions in our case. This tool is available in most GIS software programs.

\subsubsection{Openness}

Openness is somewhat similar to SVF in the sense that it depicts the "degree of dominance or enclosure of a location on an irregular surface" [57]. For positive (negative) openness calculation, the zenith (nadir) is determined for each cell, as well as surface profiles within a searched radius, along eight compass directions. For each of these, the greatest angle to the zenith (nadir) before intercepting the surface is computed (Fig. $2 \mathrm{~g}$ ). Then, the eight values are averaged. Positive, $\alpha_{R}$, and negative openness, $\beta_{R}$, are therefore expressed for a search distance $\mathrm{R}$ in each of the 8 directions ( $N$, NW, W, SW, S, SE, E, NE), as:

$\alpha_{R}=\frac{\alpha_{R}^{0}+\alpha_{R}^{45}+\cdots+\alpha_{R}^{315}}{8}$

$\beta_{R}=\frac{\beta_{R}^{0}+\beta_{R}^{45}+\cdots+\beta_{R}^{315}}{8}$

Similarly to the SVF, openness, in its two versions, shows up peaks and ridges on one hand, and valleys or holes, on the other hand, i.e. concavities and convexities. However, as described by Doneus (2011) [58], the fundamental difference with SVF lies in the fact that the maximum visible sky angle is limited to $90^{\circ}$ for the SVF (as the sky covers a half-sphere only), whereas the values of the $\alpha$ and $\beta$ angles can theoretically reach up to $180^{\circ}$. This means that a constant slope, whatever its angle, is seen as a flat terrain, as illustrated in Fig. $2 \mathrm{~h}$. This point is of primary importance in the following. These tools are available in SAGA GIS and in the free Relief Visualization Toolbox software (http://www.iaps.zrc-sazu.si/en/rvt\#v).

\subsection{Pattern-based algorithm}

\subsubsection{Geomorphons}

This method has been developed for classifying landforms using pattern recognition, rather than differential geometry [59]. In its simplest expression, the $3 \times 3$ local neighbourhood around a central cell is examined. The eight neighbours are marked as $(-)$ if they are lower, $(+)$ for higher, and (0) for equal elevation. Each cell is therefore defined by a string of eight labels, an 8-tuple pattern, representing a geomorphon, i.e. a geomorphological phenotype. The relationship between the central cell 


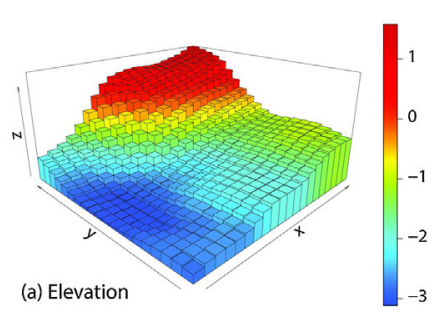

\section{Differential geometry}
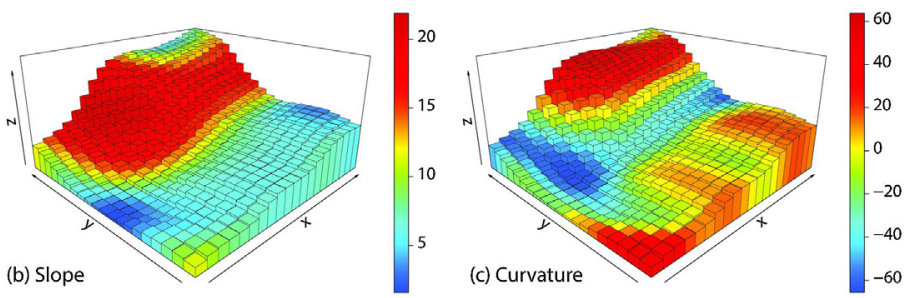

Trend removal

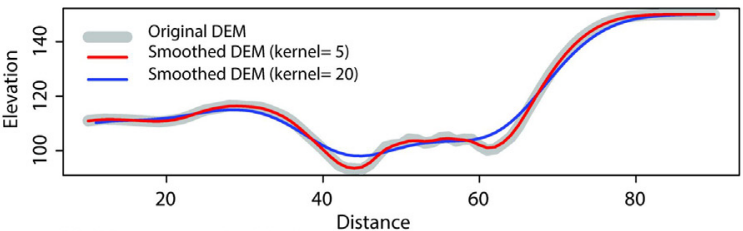

(d) DEM and smoothed DEMs

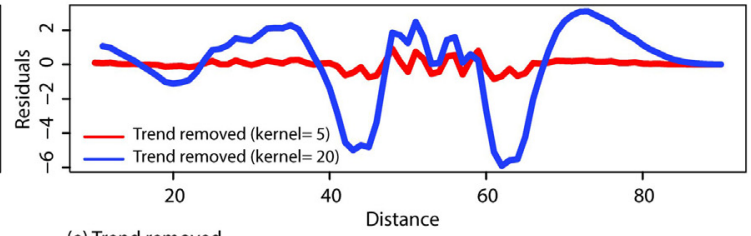

(e) Trend removed

Visibility approaches

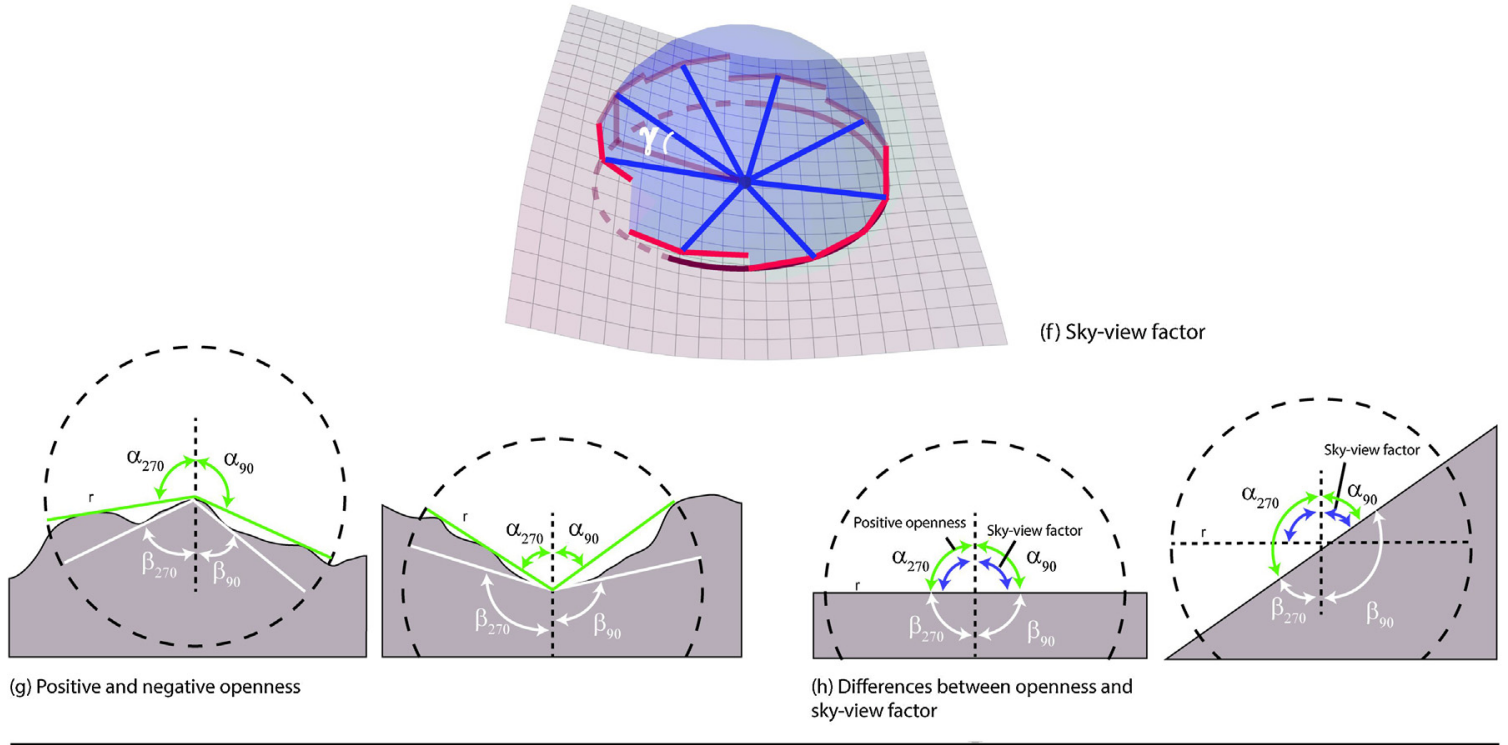

Pattern-based approach

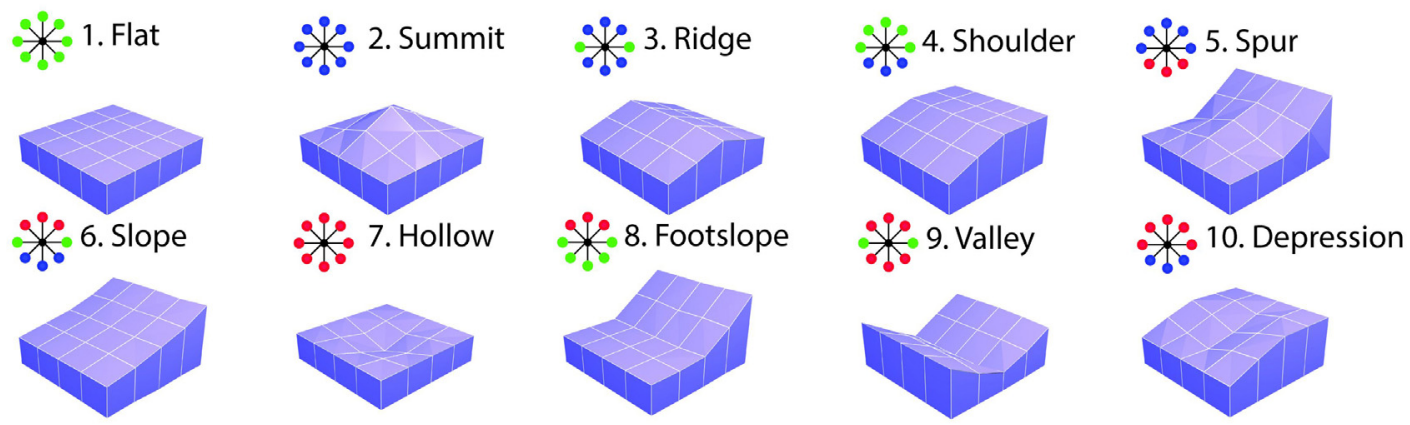

(i) the 10 most common geomorphons

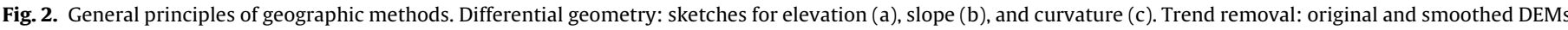

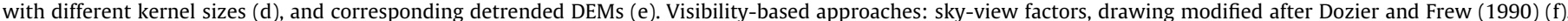

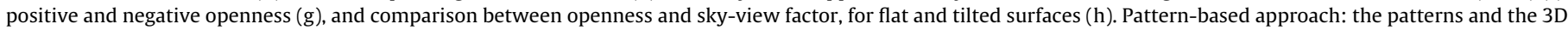
view of the 10 most common geomorphons, drawing modified after [59] (i). 
and its neighbours is based on visibility, as described above for openness [59]. At least two essential parameters must be tuned: the lookup distance, which corresponds to the maximum scale of a landform element, and the flatness threshold, below which any terrain is considered as flat. There are theoretically $3^{8}=6561$ different (ternary) patterns, but this number can be reduced to 498 because of the presence of many duplicates after rotation and/or reflection. As this number is still too high for mapping, geomorphons are grouped in classes corresponding to the ten most common landforms: flat, summit, ridge, shoulder, spur, slope, hollow, footslope, valley, and depression ([59]; Fig. 2i). This approach is tested here as it provides a discretized classification where hollows, footslopes, valleys, and depressions are more particularly sought because they may correspond to the carved areas. On the basis of this identification, the final step consisting in drawing the carved parts may be easier to handle than using continuous variables, such as those previously described. The computation of geomorphons is freely available as a GRASS add-on (https://www.grass.osgeo.org/grass72/manuals/addons/r. geomorphon.html).

\subsection{Post-processing of images}

\subsubsection{Adaptive thresholding}

In its principle, the method is quite similar to the abovementioned trend removal algorithm. The image is first blurred using a low-pass rectangular shaped filter. A binary image is then produced by comparing the difference between the original image and its filtered version, with a thresholding offset determined by the operator [60].

\subsubsection{Canny edge detector}

This procedure is popular to extract abrupt changes in grey levels, and hence, boundaries in images $[60,61]$. Here, it is used to underline the rim of the carved parts. Briefly, the image is first denoised using a square Gaussian filter. Then, the gradient intensities computed for both horizontal and vertical directions are combined to give the edge gradient and its direction. The next "non maxima suppression" step consists in removing pixels that do not have a maximum value in the direction of the gradient, which will drastically thin the edges. Finally, the edge/non-edge classification is improved by double thresholding the image in order to produce strong and weak edges. The strong edges are real edges, while the weak ones are non-edges. Then, an iterative process examines the connectivity between pixels: if pixels are connected to real edges (because edges are supposed to be continuous); they are kept as real edges, otherwise they are excluded.

\section{Results and discussion}

\subsection{Testing the algorithms on a small part of a real-world artefact}

Stela No. 35 standing at Tsatsiin Ereg was chosen as the first candidate to evaluate the algorithms and to understand their effects on a real-life carved surface. This is one of the stelae where the relief is best marked. A window of about $30 \times 6 \mathrm{~cm}^{2}$ was selected to present a clear decor lying on a curved surface, characterised by a pronounced slope to the left ( $\Delta \mathrm{h} \sim 5 \mathrm{~cm}$, see the longitudinal elevation profile of the DEM, Fig. 3a).

The slope map (Fig. 3b), which represents the local magnitude of the maximum gradient in degrees, underlines the features of interest, more particularly in the right (rather flat) part, but becomes dominated by the overall slope in the left part, as depicted by the evolution of the longitudinal profile. The influence of the overall slope makes the slope map inappropriate to detect local features on irregular surfaces. The profile curvature (Fig. 3c) better highlights the concave and convex parts of the stone, but is still influenced by the overall slope, becoming gradually obliterated in the extreme left part. Because of the window size ( $1 \mathrm{~cm}$ of radius) the details have vanished. Using a smaller kernel (not shown here) would bring them to light, but would also increase noise. In addition, a low radius value would produce flat (and not concave as they should be) classifications at the deepest part of the holes, which would obscure the interpretation of the map. The two following panels correspond to trend removal with a window of $1 \mathrm{~cm}$ radius (this size was chosen to capture the carved parts) by using a Gaussian filter, and LRM procedure (Fig. 3d and e). In both cases, the left part of the surface is no longer affected by the overall slope, which is precisely the aim of the process. The local features are well enhanced but they may suffer from shifts and artefacts (in white in 3d and e), as mentioned above (see Fig. 2e). A better signal-to-noise ratio is observed with the use of the Gaussian filter alone, limiting the interest of using LRM, at least in our case.

The sky-view factor (Fig. 3f) correctly reveals the carved and protruding parts lying on the rather flat surface, but as by nature it refers to a horizontal plane, it lacks detail, becoming completely obscured in the left, sloped part. This is not the case for positive openness (Fig. 3g), where the entire surface is seen as if no overall trend existed. This is because the zenith is taken as reference instead of the horizon. Negative openness, by nature, mainly highlights the deepest parts of the carved areas and, to some extent, the flat surfaces. It succeeds adequately in this task, as displayed in Fig. 3h. However, an archaeological drawing is expected to start from the rim of the carved surface, and not only from the deepest part of the incision, so that this representation, although quite efficient in other circumstances, is not well adapted to our purpose.

The surface treatment based on pattern recognition around each cell can obviously not be operated from an original DEM exhibiting a strong overall slope, otherwise most of the map would be classified as slope, and structures lying on it would not be recognised at all. For that reason, geomorphons are computed from the detrended DEM (Fig. 3d). The ten most common features are depicted in Fig. 3i. Only the five corresponding to carved parts: i.e. slopes, hollows, footslopes, valleys, and depressions (features No.6-10) are retained to form a binary image (Fig. $3 \mathrm{j}$ ), which contains noise, but extracts the carved structures reasonably well.

To sum up this first evaluation, slope, profile curvature and skyview factor do not constitute appropriate treatment for a general case, where overall slope or oscillating/irregular surfaces may be involved, but could be useful for carved plane surfaces. To go further with the other algorithms, the entire side of the stela is taken into account, and a close-up is performed near the edge, where the slope abruptly changes to form another side (Fig. 4). While positive openness (Fig. 4a), trend removal (Fig. 4c) and geomorphons (Fig. 4d) provide a readable overall picture, even close to the edges, the LRM procedure fails in this task (Fig. 4b), as the image is less clear. Although the LRM method has proved to be quite powerful for identifying small features in complex DEMs [58], and for petroglyphs, more specifically on flat surfaces [62], it is not able to properly depict the deer carved on the highly sloped part, so this approach is discarded in the following. For trend removal, the application of a simple Gaussian filter with appropriate kernel size appears more efficient, although positive artefacts (in white) appear, as expected, at the angle of the stela (Fig. 4c). The geomorphon method performs well (Fig. 4d), but its purged binary version, concentrating on negative anomalies, is too noisy to be really useful as a basis for a final drawing (Fig. 4h). Positive openness seems therefore to be the best choice (Fig. 4a). The fact that positive openness disregards the general topography can be a problem for the overall readability of natural landscapes [58]. This potential drawback is an asset here, as highlighting anomalies, preferentially negative (i.e. the carved 


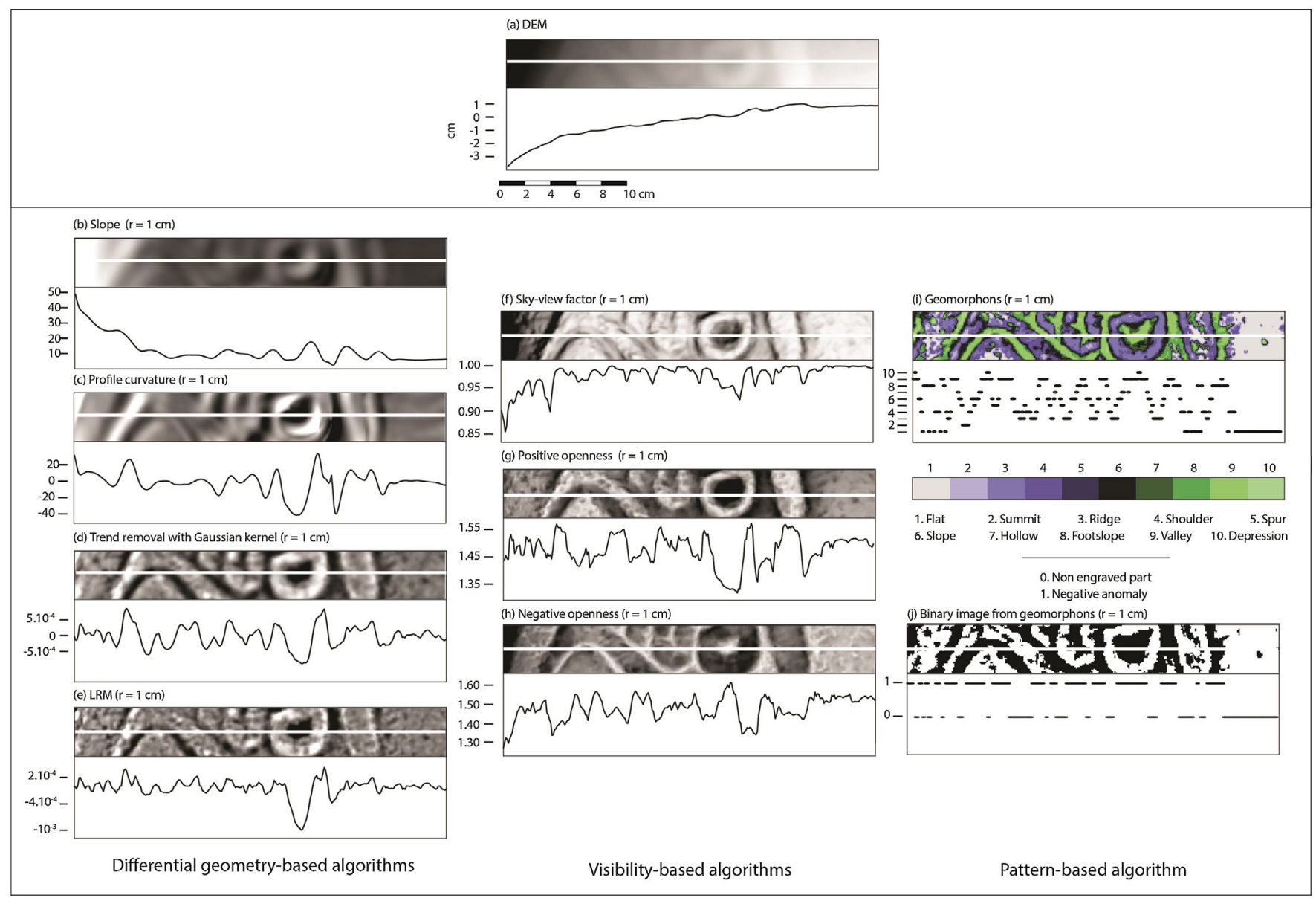

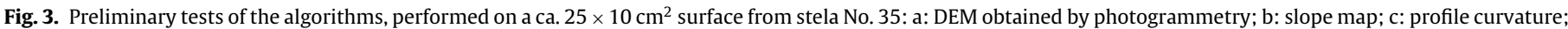

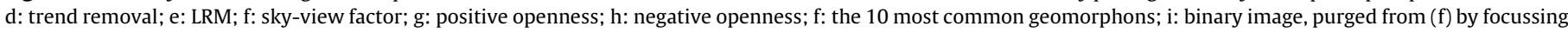
on negative anomalies.

surfaces), is the goal. The relief is then visually apprehended, simply by the geometric deformation of carved symbols lying on the edges of the stone.

One last treatment step was tentatively applied in order to facilitate the production of the final archaeological documentation. It consists in simplifying the information, either by colouring, as precisely as possible, the carved areas, or by detecting the rim of the carved parts. Both positive openness and trend removal maps are produced from continuous quantitative variables, so that any attempt at automatic drawing is expected to involve more or less complex additional treatments based on thresholding and/or edge detection. The first attempt was conducted on the positive openness map by applying an adaptive thresholding function. The result is readable (Fig. 4e), but needs to be thoroughly cleaned and completed with a raster graphics editor, before becoming completely acceptable (note that several tests were performed with different window sizes and thresholding offsets without better success). A better option probably consists in detecting the edges of the image. Canny edge detection applied to both positive openness and trend removal maps (Fig. $4 \mathrm{f}$ and $\mathrm{g}$, respectively) produces comparable images, which constitute a suitable basis for the final drawing, a step inevitably performed by hand. Experiments indicate that the best solution always consists in choosing elevated thresholds during the Canny edge detection procedure. Even if true edges are forgotten, it is much easier to manually fill in the missing parts during the final drawing process than to eliminate unwanted noise.

\subsection{Full evaluation on three different examples}

Figs. 5 and 6 illustrate the entire procedure, including the final drawing, for stela No. 35 from Tsatsiin Ereg, and for stela S7 from Uushgiin Uvur, another Mongolian archaeological site. Most of the symbols carved on the surface of stela No. 35 are readily distinguishable in the orthomosaics, because of the colour variations between the carved parts and the rest of the stela (Fig. 5a). Even if this archaeological information is somewhat visible, this representation cannot efficiently be used alone for documentation. The positive openness maps clearly depict the symbols, the surface finish of the stela, and the structural information of the stone, such as irregularities and cracks (Fig. 5b). As the rock topography is rather regular and the symbols well marked, the Canny edge detection applied to positive openness maps succeeds in delineating properly most of the symbols (Fig. 5c). This Canny edge raster image is vectorised, using for example a vector graphic editor, such as Adobe Illustrator, and placed over a low opacity layer with positive openness (Fig. 5d), before being reworked in the vector graphics editor. At that step, the aim is to close the edges remaining open in order to produce the final vectorised drawing (Fig. 5e). The resulting image is almost perfectly identical to the drawing produced after time-consuming rubbing (Fig. 5f).

The figures carved on stela S7 are much less clear, and often even invisible in the orthomosaics (Fig. 6a). Most of them are brought to light with positive openness, except in places where the stone surface has been strongly altered or damaged (Fig. 6b). 

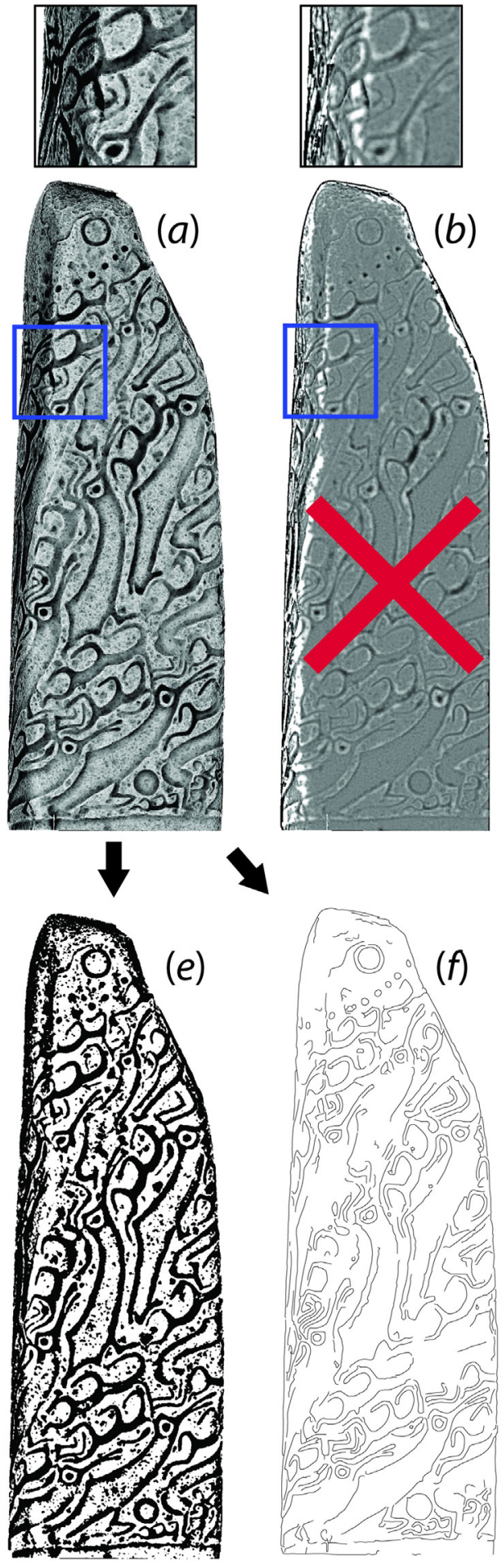
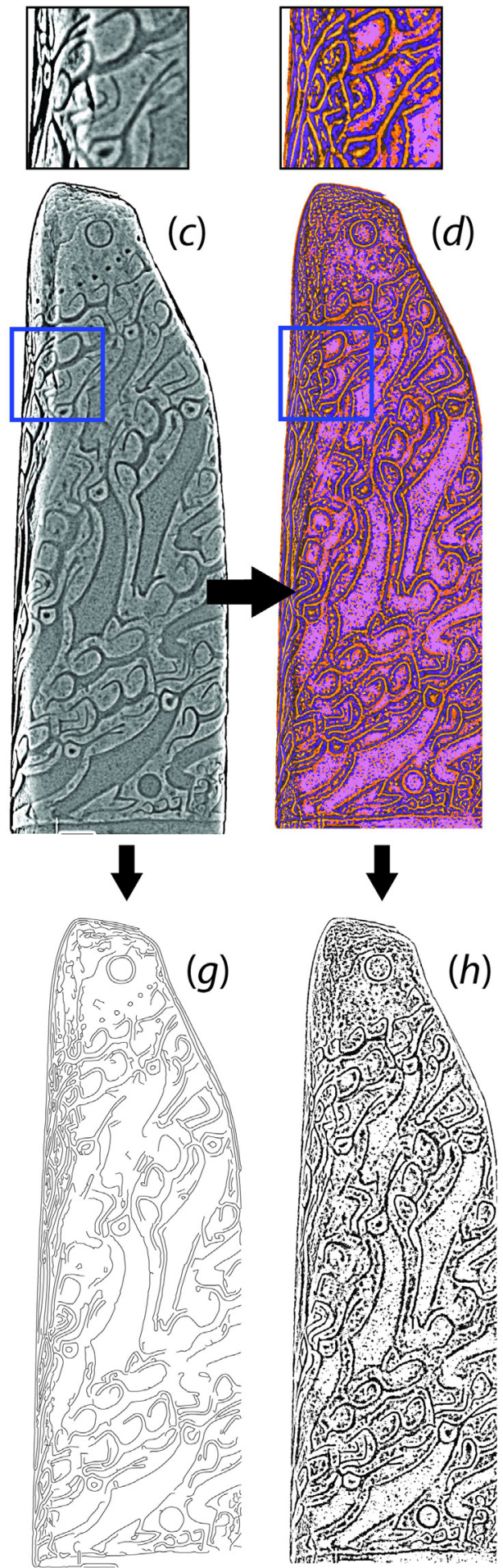

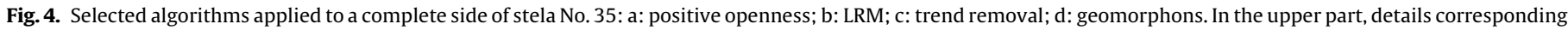

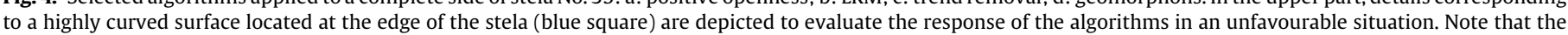

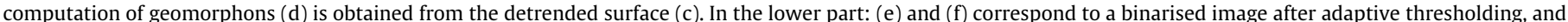

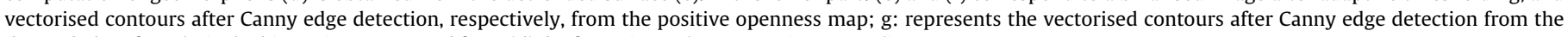
detrended surface; h: is the binary image, purged from (d), by focussing only on negative anomalies.

The Canny edge detection algorithm introduces more noise than in the case of stela No. 35, because of the stone's poorer state of conservation, and the lower depth of carving (Fig. 6c). The case of stela S7 is less favourable for the semi-automatic drawing step (Fig. 6d). However, the final drawing (Fig. 6e) is again quite comparable with the existing archaeological documentation, obtained after tracing (Fig. 6f), although some differences can be observed in the trickiest, most damaged parts: the head of a deer, and the antlers of another animal are distinguished by positive openness, but not in the archaeological documentation [35]. In contrast, these authors depicted the back of a third deer, including its leg, which cannot be seen by positive openness. Generally, the overall deer shapes are more accurate with our method. 
(a) Orthophotography
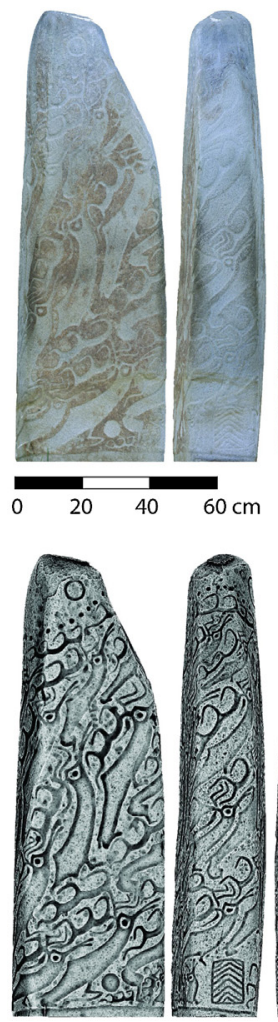

(b) Positive openness (c) Canny edge detection
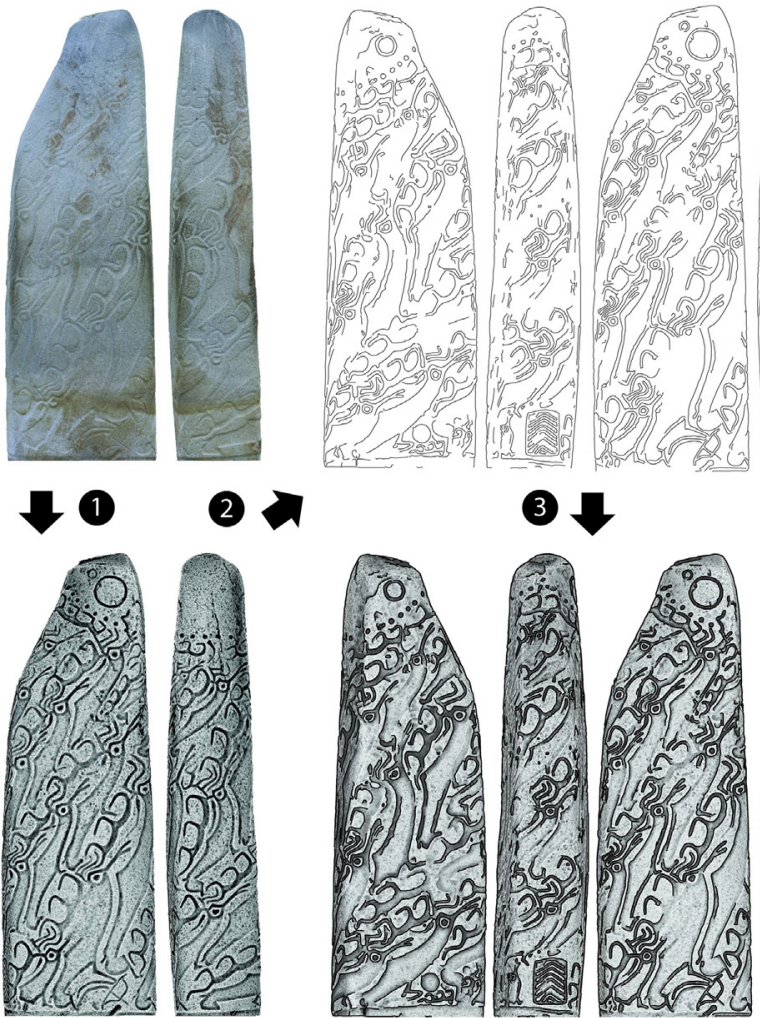

(d) Canny edge detection + Positive openness as background ( $50 \%$ opacity) (e) Cleaning of the vectorized drawing
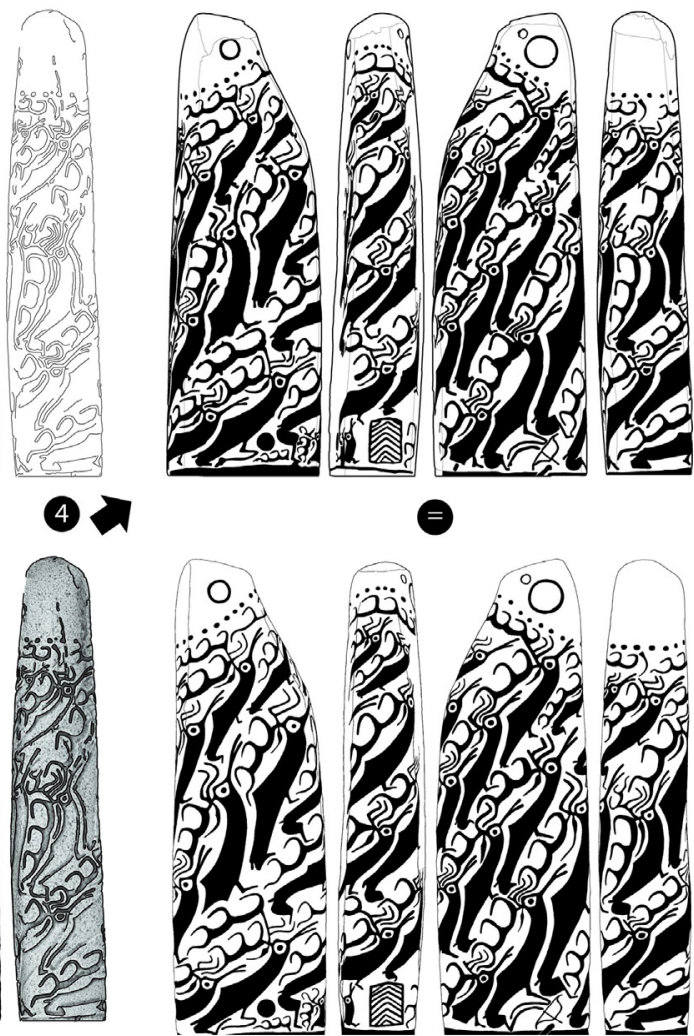

(f) Existing archaeological documentation

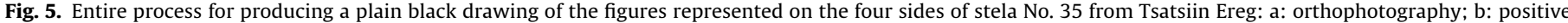

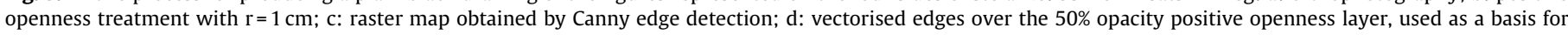

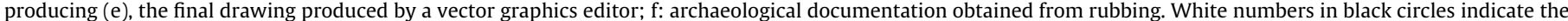
workflow.

(a) Orthophotography
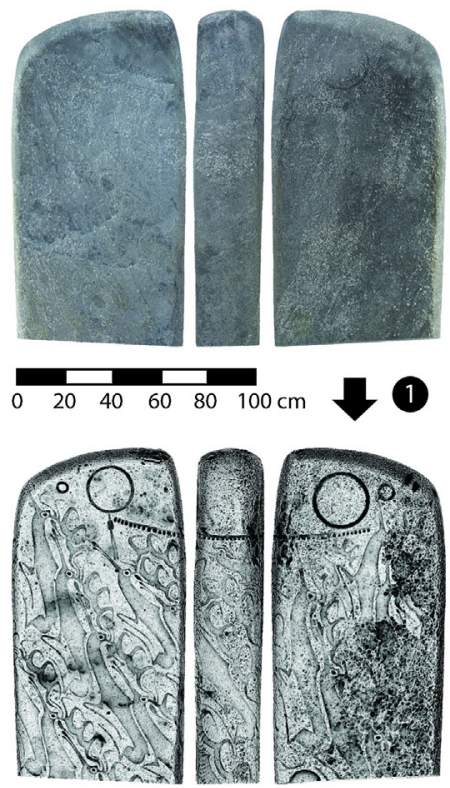

(b) Positive openness

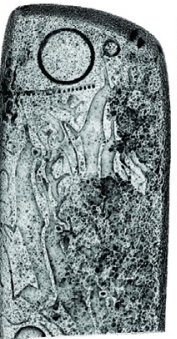

(c) Canny edge detection

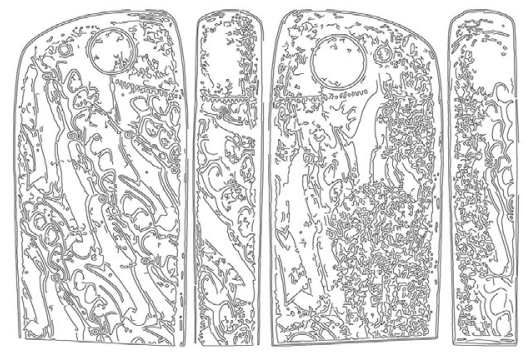

2 -

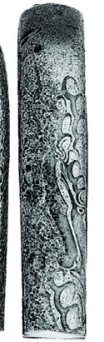

3

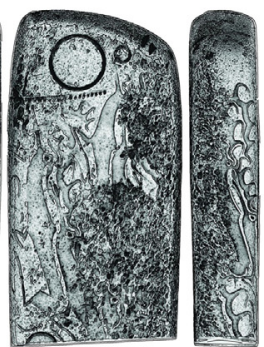

(d) Canny edge detection + Positive openness as background (50\% opacity) (e) Cleaning of the vectorized drawing
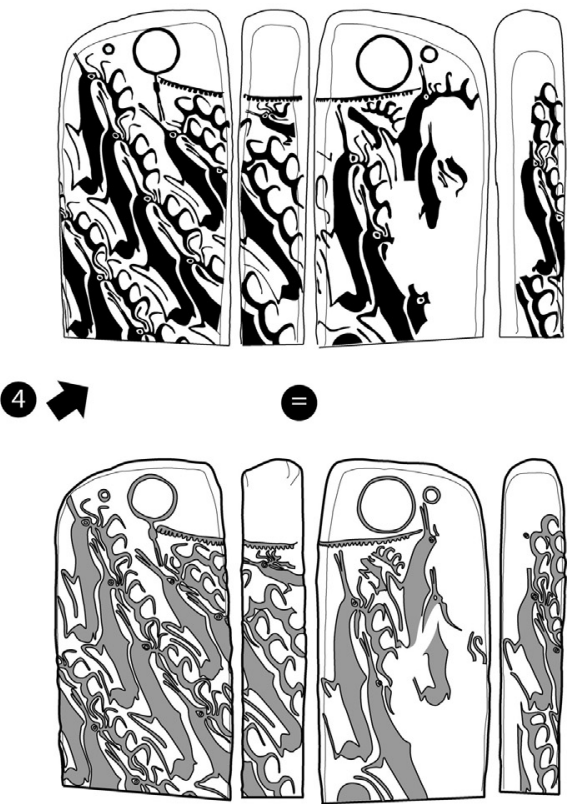

(f) Existing archaeological documentation

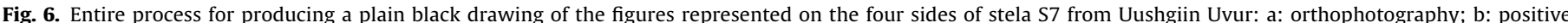

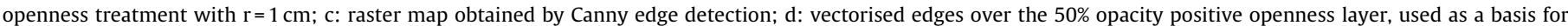

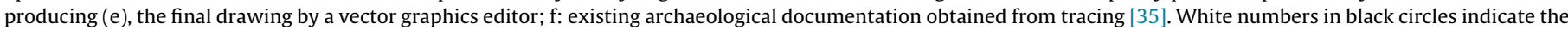
workflow. 


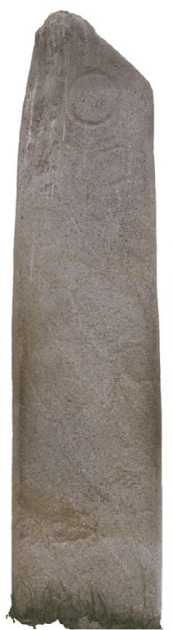

(a)

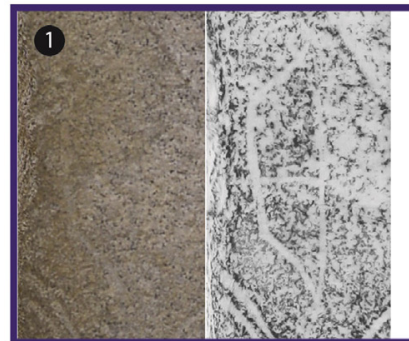

(d)
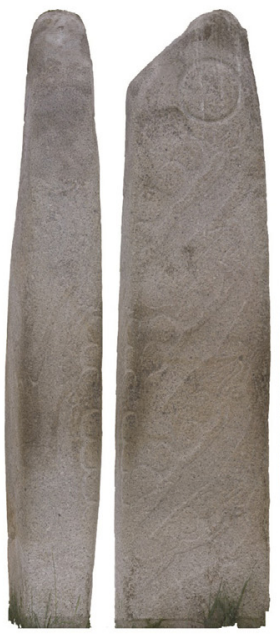

$\overline{20} \mathrm{~cm}$
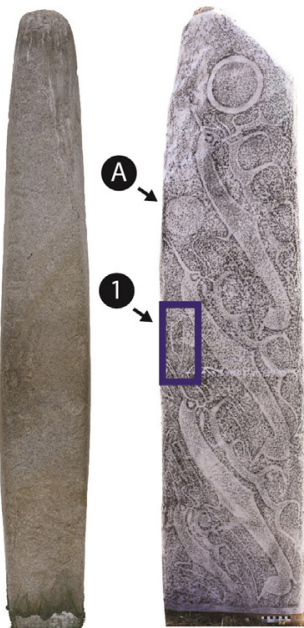

(b)

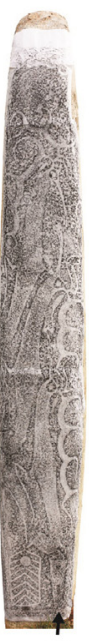

B

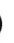

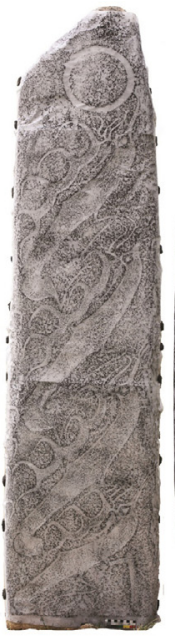

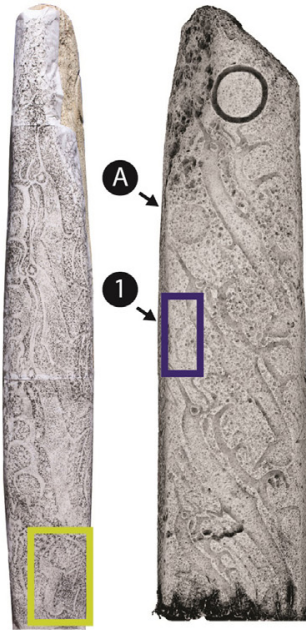

(c)

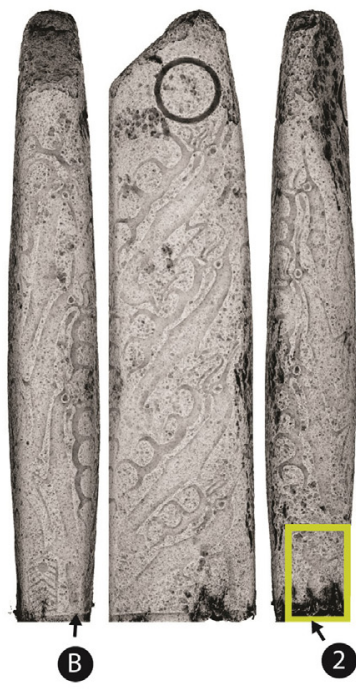

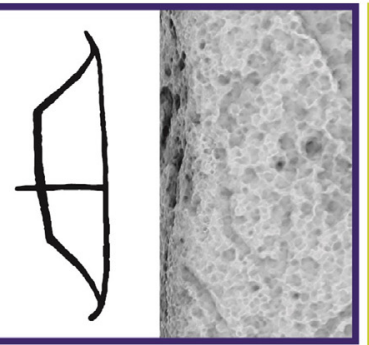

(e)

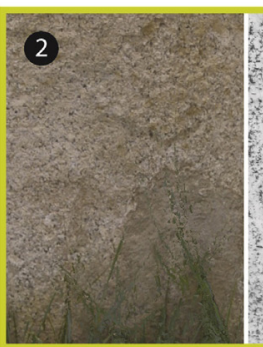

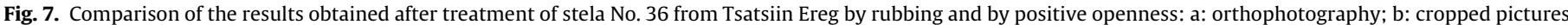

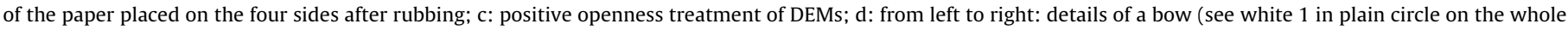

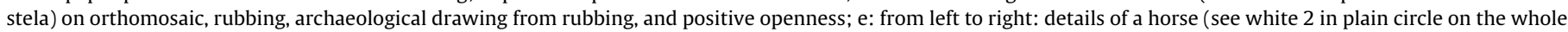

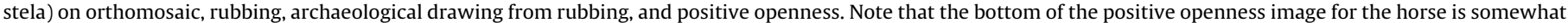
obscured by the presence of grass; white A and B in plain circles point out special symbols: a disk and an axe, respectively.

The last example compares the results obtained by rubbing and after positive openness treatment for stela No. 36 from Tsatsiin Ereg. The relief of the carved parts of this stela is not strongly marked, so that the figures can barely be distinguished by the naked eye in orthomosaics (Fig. 7a). However, the stela is well preserved, facilitating symbol identification. Rubbing allows all the features to be clearly distinguished (Fig. 7b). This is not the case in some areas for the positive openness maps (Fig. 7c). Note that, as the relief is not pronounced, the Canny edge detection step is not recommended, because it would introduce more noise than signal. Even if the bow, located at mid-height of the stela, is distinguished by positive openness (mark 1 on Fig. 7b-d), its arrow cannot be identified, contrary to the much clearer image provided by rubbing. Note that the whole symbol is almost imperceptible on the orthomosaic (Fig. 7d). The differences between the two approaches (rubbing and positive openness treatment) are even more obvious for the horse carved at the foot of the stela (mark 2 on Fig. 7b, c and e), where only the animal's anterior paw and its body are recognisable by positive openness, and just scarcely guessed on the orthomosaic (Fig. 7e). The image provided by rubbing is noisy, but more complete, allowing the entire horse figure to be properly drawn. Rubbing produces better results, especially when performed by an experienced archaeologist, who spontaneously insists on discrete features to highlight them. Despite the undeniable overall quality of the rubbing output, the time required, especially in the field, is a limiting factor. From Table 1, which summarises the time required for each method and their respective outputs, it is obvious that $3 \mathrm{D}$ modelling is better adapted for extensive rock art documentation, as acquisition takes minutes, whereas several hours are necessary
Table 1

Time necessary for processing and results produced.

\begin{tabular}{lll}
\hline & Rubbing & This method \\
\hline Field work & & \\
Acquisition & $\sim 4 \mathrm{~h}^{\mathrm{a}}$ & $5-15 \mathrm{~min}$ \\
Lab. work & & $3 \mathrm{~h}^{\mathrm{b}}$ \\
3D modelling & - & $20 \mathrm{~min}$ \\
Map construction & - & $10 \mathrm{~min}^{\mathrm{a}}$ \\
Edge detection & $\sim 2$ days & $\sim 1$ day $^{\mathrm{c}}$ \\
2D drawing & Pictures2D drawing & Pictures \\
Results produced & & $3 \mathrm{D}$ model \\
& & Orthomosaics \\
& & 2D drawing
\end{tabular}

\footnotetext{
a For a medium stela of about $1.5-2 \mathrm{~m}$ high.

b For approximately 30-40 pictures (note that most of the operations do not require the presence of the operator).

c May be much less if the vectorisation of carved parts is possible.
}

to document a single stela by rubbing. Moreover, now that digital recording techniques are readily available at a high level of accuracy and low cost, methods implying contact with the rock should be not recommended as a standard, because in some cases (depending on the stone, presence of cracks and hollows under the surface, etc.) they may irremediably damage the carved surfaces. The 3D process produces accurate orthomosaics and 3D models, which can effectively supplement the traditional paper documentation with companion web pages, for example. It is worth mentioning that the time required for calculation in the laboratory should not be con- 

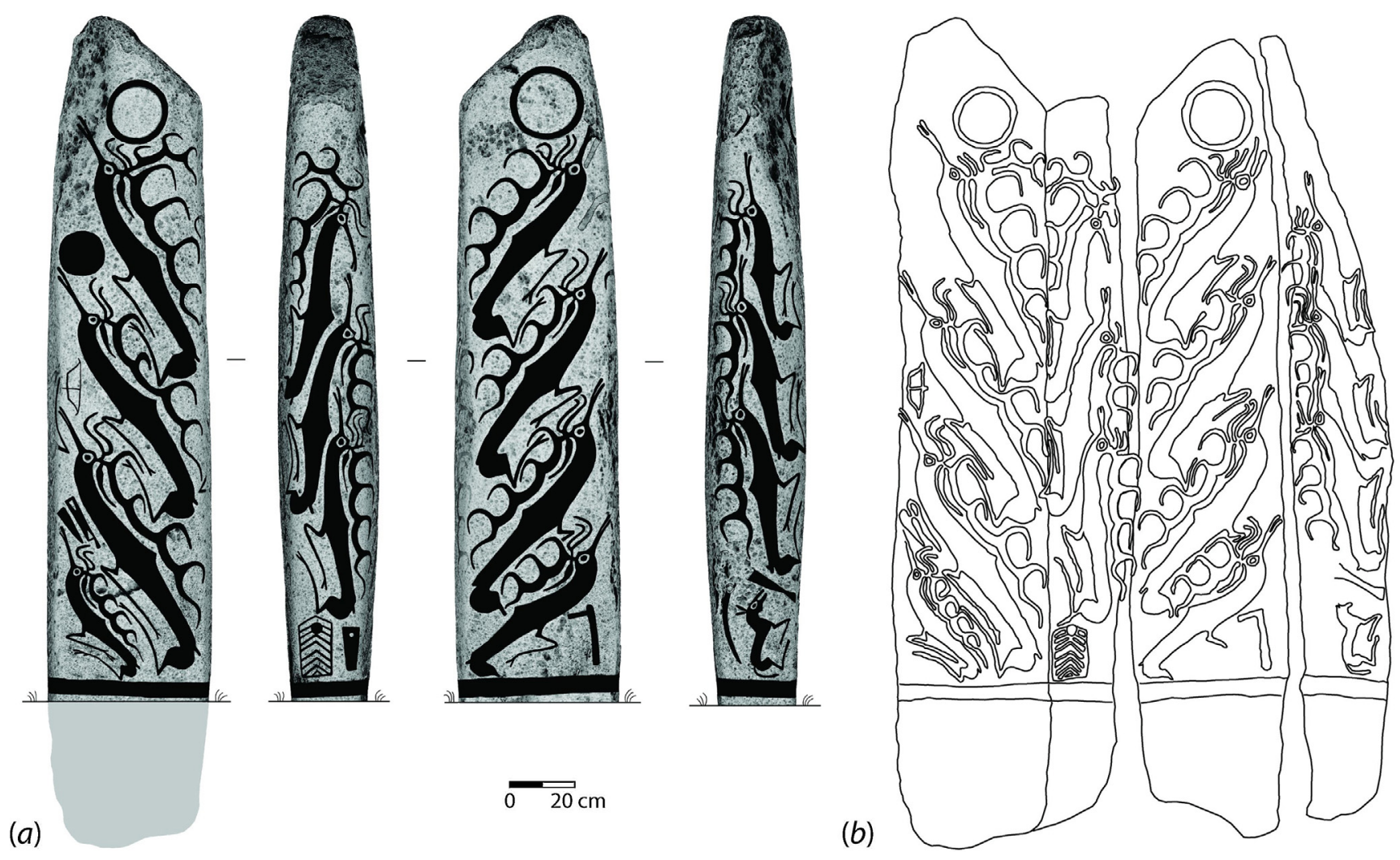

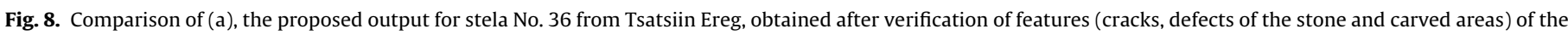

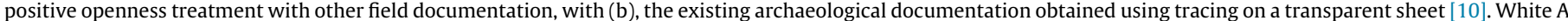

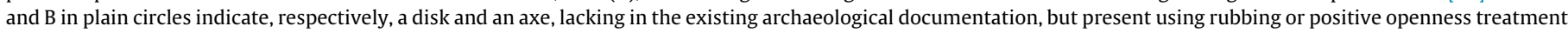
(see Fig. 7).

sidered as an obstacle, because the presence of the operator is not always necessary. Unfortunately, it takes almost a day to rework the images provided by positive openness or rubbing, although $20-30 \%$ of this time can be saved if the drawing starts from vectorised edges, where available.

However, as demonstrated by Fig. 7, rapid 3D modelling may sometimes fail to fully capture discrete but important details, in the most challenging situations. In such cases, it is possible to go back to small, problematic areas, and supplement the overall information provided by DEM computation. The best solution might be additional 3D modelling by photogrammetry, restricted to the problem area, but with a lower distance between the camera and the object, so that the resolution is improved, or by applying techniques based on pictures taken with oblique light from different directions. Such a combination takes advantage of both approaches, while maintaining a rapid workflow in the field.

Moreover, when used as background, positive openness displays well the surface condition of the stones, the second important factor in rock art research. On top of this layer, engraved figures can be drawn in plain black to facilitate interpretation, as shown in Fig. 8a. Such a document can only produced after a verification step, in which the operator compares positive openness treatment with field documentation (close-up photos of the rock surfaces or rubbings) to ensure that cracks or depressions in the rock surface are not depicted as engravings, and that no detail of the engravings is lost. We propose this original method of representation as a new reference for documentation, more informative than the traditional method of crude black and white binary images (e.g. Fig. 8b). It is worth mentioning that, in this example, tracing did not respect the overall geometry of the stone. The disk (mirror) and the axe (marks
A and B) were not illustrated, although they were properly identified by both rubbing and positive openness (marks A and B in Fig. 7b and $\mathrm{c}$ ).

\section{Conclusion}

A simple pipeline is provided here for the acquisition of photorealistic 3D models of carved stones by photogrammetry. Briefly, it consists in modelling the object of interest by photogrammetry, producing DEMs, calculating positive openness, detecting edges on positive openness maps if they are clear enough, and reworking with a vector graphic editor to produce the final document. The technique is not invasive, and is easy to implement in the field. It provides accurate models, able to capture most of the finest details in the 3D geometry of rock surfaces. The objects of interest are split into several $2.5 \mathrm{D}$ raster maps, which can be freely arranged depending on the overall geometry, and treated by common algorithms developed for geomorphological studies. Positive openness appears to be the most versatile algorithm to highlight the carved parts, particularly for curved or irregular surfaces. The resulting map, built on the basis of a continuous variable, may profitably go through a delineation step. If the carved parts are sufficiently marked, this step can notably accelerate the drawing process. Otherwise, the operator must still delineate all the figures with a vector graphics editor. This potential weakness should not be seen as a major drawback, because the most limiting factor is the time spent in the field, especially for studies undertaken overseas, where field campaigns are often time-constrained. The method proposed here is far more rapid than traditional acquisition based on rubbing or tracing. In favourable cases, the final results obtained at the end of the process 
are comparable to the best drawings available, and will probably outperform many standard representations, especially for their geometry. If necessary, problematic parts can be complemented by another photogrammetry session, closer to the object, in order to obtain a higher resolution, or by using more standard techniques, based on pictures taken with oblique lights coming from several directions. Note that our method does not require a high level of expertise, eliminating one of the main bottlenecks for extensively recording rock art. More than simply complementing the usual techniques, our 3D modelling approach opens up new perspectives. For instance, the combination of these drawings with the depiction of the surface condition is proposed as a new reference for rock art documentation. In addition to the traditional 2D archaeological documentation, the photorealistic 3D models produced can easily be used to compute volumes, measure distances, and also be processed by more complex morphometrics-based analyses, or for treating complex cases where engravings are superimposed. The 3D models provide information for degradation surveys, and can be exchanged between researchers, shared with the public on the web, and printed or integrated into 3D virtual scenes.

\section{Acknowledgements}

We are grateful to the anonymous reviewers whose judicious comments have improved the manuscript.

\section{References}

[1] UNESCO, Basic Texts of the 1972 World Heritage Convention, UNESCO, Paris, 2016.

[2] UNESCO, Convention on the means of prohibiting and preventing the illicit import, export and transfer of ownership of cultural property, UNESCO, Paris, 1970

[3] J. Clottes, Occasional Papers for the World Heritage Convention, l'art rupestre une étude thématique et critères d'évaluation, Foix, ICOMOS, 2002, pp. 15.

[4] The UNESCO, Courier, Primeval art, rock painting and engraving, 51, 1998, pp. 4.

[5] G. Plets, G. Verhoeven, D. Cheremisin, R. Plets, J. Bourgeois, B. Stichelbaut, W. Gheyle, J. De Reu, The deteriorating preservation of the altai rock art: assessing three-dimensional image-based modelling in rock art research and management, Rock Art Res. 29 (2012) 139-156.

[6] E. Wieser, M. Seidl, M. Zeppelzauer, A study on skeletonization of complex petroglyph shapes, Multimed. Tools Appl. 76 (2017) 8285-8303.

[7] M. Seidl, E. Wieser, C. Alexander, Automated classification of petroglyphs, Digit. Appl. Archaeol. Cultur. Herit. 2 (2015) 196-212.

[8] M. Seidl, C. Breiteneder, Automated petroglyph image segmentation with interactive classifier fusion, in: Proceedings of the Eighth Indian Conference on Computer Vision, Graphics and Image Processing. No. 66, 2012.

[9] E. Jacobson, V.D. Kubarev, D. Tseveendorj, Mongolie du Nord-Ouest: Tsagaan Salaa/Baga Oigor, 2, De Boccard, Paris, 2001 (Répertoire des Pétroglyphes d'Asie centrale, Fascicule no. 6. Jakov A. Sher and Henri-Paul Francfort, Editors).

[10] J. Magail, J.-O. Gantulga, C. Yeruul-Eredene, M. Tsengel, Inventaire et relevés des pierres à cerfs de Tsatsyn Ereg, Bull. Musee Anthropol. Prehist. Monaco 50 (2010) 77-114.

[11] S. Cassen, L. Lescop, V. Grimaud, G. Robin, Complementarity of acquisition techniques for the documentation of Neolithic engravings: lasergrammetric and photographic recording in Gavrinis passage tomb (Brittany, France), J. Archaeol. Sci. 45 (2014) 126-140.

[12] M. Díaz-Guardamino, L. García Sanjuán, D. Wheatley, V. Rodríguez Zamora, RTI and the study of engraved rock art: A re-examination of the Iberian southwestern stelae of Setefilla and Almad? de la Plata 2 (Seville, Spain), Digit. Appl. Archaeol. Cultur. Herit. 2 (2015) 41-54.

[13] S. Cassen, G. Robin, Recording art on neolithic stelae and passage tombs from digital photographs, J. Archaeolog. Method Theory 17 (2010) 1-14.

[14] H. Pires, J.M. Rubio, A.E. Arana, Techniques for revealing 3D hidden archaeological residual models as virtual-polynomial texture maps, Int. Arch. Photogramm. Remote Sens. Spat. Info. Sci. XL-5/W4 (2015) (3D Virtual Reconstruction and Visualization of Complex Architectures, 25-27 February 2015, Avila, Spain, 2015).

[15] G. Pavlidis, A. Koutsoudis, F. Arnaoutoglou, V. Tsioukas, C. Chamzas, Methods for 3D digitization of cultural heritage, J. Cult. Herit. 8 (2007) 93-98.

[16] N. Yastikli, Documentation of cultural heritage using digital photogrammetry and laser scanning, J. Cult. Herit. 8 (2007) 423-442.

[17] F. Remondino, A. Rizzi, Reality-based 3D documentation of natural and cultural heritage sites-techniques, problems, and examples, Appl. Geomat. 2 (2010) 85-100.
[18] I. Domingo, V. Villaverde, E. L?ez-Montalvo, J.L. Lerma, M. Cabrelles, Latest developments in rock art recording: towards an integral documentation of Levantine rock art sites combining 2D and 3D recording techniques, J. Archaeol. Sci. 40 (2013) 1879-1889.

[19] G. Plets, W. Gheyle, G. Verhoeven, J. De Reu, J. Bourgeois, J. Verhegge, B. Stichelbaut, Three-dimensional recording of archaeological remains in the Altai Mountains, Antiquity 86 (2012) 884-897.

[20] S. Soler, F.J. Melero, M.L. Luzón, A complete 3D information system for cultural heritage documentation, J. Cult. Herit. 23 (2017) 49-57.

[21] B. Cyganek, J.P. Siebert, An Introduction to 3D computer vision techniques and algorithms, John Wiley \& Sons, Ltd, 2009, pp. 483.

[22] G. Petrie, T.J.M. Kennie, Terrain modelling in surveying and civil engineering, McGraw-Hill Ed., 1991, pp. 351.

[23] D.J. Savory, Digital terrain classification via scale-sensitive edge detection: hillslope characterization for soil-landscape analysis, University of WisconsinMadison, 1992, pp. 330.

[24] P. Longley, Geographic information systems and science, John Wiley \& Sons, 2005, pp. 560.

[25] R. Szeliski, Computer vision - Algorithms and applications, Springer, 2011, pp. 812.

[26] B. Jähne, H. Haussecker, Computer vision and applications. A guide for students and practitioners, Academic press, 2000, pp. 679.

[27] H.F.R. Beaubien, B.V. Karas, 3D scanning of deer stones on the Mongolian steppe, Objects Special. Group Postprints 17 (2007) 178-196.

[28] S. Green, A. Bevan, M. Shapland, A comparative assessment of structure from motion methods for archaeological research, J. Archaeol. Sci. 46 (2014) $173-181$.

[29] J.L. Lerma, C. Muir, Evaluating the 3D documentation of an early Christian upright stone with carvings from Scotland with multiples images, J. Archaeol. Sci. 46 (2014) 311-318

[30] J. Fernández-Lozano, G. Gutiérrez-Alonso, M. Ángel Ruiz-Tejada, M. CriadoValdés, 3D digital documentation and image enhancement integration into schematic rock art analysis and preservation: The Castrocontrigo Neolithic rock art (NW Spain), J. Cult. Herit. 26 (2017) 160-166.

[31] M.J. Westoby, J. Brasington, N.F. Glasser, M.J. Hambrey, J.M. Reynolds, 'Structure-from-Motion' photogrammetry: A low-cost, effective tool for geoscience applications, Geomorphology 179 (2011) 300-314.

[32] K. Kraus, Photogrammetry geometry from images and laser scans. Walter de Gryter Ed., 2nd ed., 2007, pp. 459.

[33] I. Florinski, Digital terrain analysis in soil science and geology, 2nd ed, Academic Press, 2016, pp. 506.

[34] V.V. Volkov, Olennye kamni Mongolii, Nauchnyi mir, Moscow, 2002, pp. 248 (in Russian)

[35] S. Takahama, T. Hayashi, M. Kawamata, R. Matsubara, D. Erdenebaatar, Preliminary Report of the Archaeological Investigations in Ulaan Uushig (Uushigiin Övör) in Mongolia, Kanazawa University, 2006.

[36] J. Magail, Tsatsiin Ereg, site majeur du début du 1er millénaire en Mongolie, Bull. Musee Anthrop. Prehist. Monaco 48 (2008) 107-120.

[37] T. Turbat, J. Bayarsaikhan, D. Batsukh, N. Bayarkhuu, Deer stones of the Jargalantyn Am, Mongolian Tangible Heritage Association NGO, Ulaanbaatar, 2011, pp. 192.

[38] Y. Esin, J. Magail, C. Yeruul-Erdene, J.O. Gantulga, Paint on deer stones of Mongolia, Archaeol. Ethnol. Anthropol. Eurasia 45 (2017) 379-389.

[39] J. Magail, Les stèles ornées de Mongolie dites " pierres à cerfs ", de la fin de l'âge du Bronze. Actes du $3^{\mathrm{e}}$ Colloque de Saint-Pons-de-Thomières, 2012, Saint-Ponsde-Thomières, France, 2015, pp. 89-101.

[40] J. Magail, La mission archéologique conjointe Monaco - Mongolie, recherches scientifiques et leur applications dans la valorisation du patrimoine, Rev. CNRS Chine 19 (2015) 57-61 (dépasser les frontières)

[41] S. De Luca, La photomodélisation architecturale. Relevé, modélisation et représentation d'édifices à partir de photographies, Eyrolles, 2009, pp. 263.

[42] C. Wu, VisualSFM: a visual structure from motion system, 2011 (http://www.ccwu.me/vsfm)

[43] Y. Furukawa, J. Ponce, Accurate, dense, and robust multiview stereopsis, IEEE Trans. Pattern Anal. Mach. Intell. 32 (2010) 1362-1376.

[44] Y. Furukawa, B. Curless, S.M. Seitz, R. Szeliski, IEEE conference on computer vision and pattern recognition, 2010, pp. 1434-1441.

[45] J.L. Lerma, S. Navarro, M. Cabrelles, V. Villaverde, Terrestrial laser scanning and close range photogrammetry for 3D archaeological documentation: the upper Palaeolithic cave of Parpallo as a case study, J. Archaeol. Sci. 37 (2010) 499-507.

[46] J.L. Lerma, S. Navarro, A.E. Segui, M. Cabrelles, Range-based versus automated markerless image-based techniques for rock art documentation, Photogramm. Rec. 29 (2014) 30-48.

[47] B.J. Devereux, G.S. Amable, P. Crow, Visualisation of LiDAR terrain models for archaeological feature detection, Antiquity 82 (2008) 470-479.

[48] R. Hesse, LiDAR-derived local relief models - A new tool for archaeological prospection, Archaeol. Prospect 17 (2010) 67-72.

[49] B. Sittler, Revealing historical landscapes by using airborne laser scanning. A 3-D model of ridge and furrow in forests near Rastatt (Germany), Int. Arch. Photogram. Remote Sens. Spat. Info. Sci. XXXVI (8/W2) (2004) 258-261.

[50] B. Stular, Z. Kokalj, K. Ostir, L. Nuninger, Visualization of lidar-derived relief models for detection of archaeological features, J. Archaeol. Sci. 39 (2012) 3354-3360.

[51] E. Imhof, Cartographic relief presentation. Environmental Systems Research Institute Inc., U. S., 3rd Ed, ESRI Press, Redlands, 2007, pp. 434. 
[52] K. Zakšek, K. Oštir, Ž. Kokalj, Sky-view factor as a relief visualization technique, Remote Sens. 3 (2011) 398-415.

[53] M.J.D. Smith, M.F. Goodchild, P. Longley, Geospatial analysis: a comprehensive guide to principles techniques and software tools, Troubador Publishing Ltd, 2007, pp. 516.

[54] Ž. Kokalj, R. Hesse, Airborne laser scanning raster data visualization. A Guide to Good Practice. Institute of Anthropological and Spatial Studies, Internet Publication, 2017, pp. 90.

[55] T.E. Oke, Boundary layer climates, Routledge Ed, 1987, pp. 464

[56] J. Dozier, J. Frew, Rapid calculation of terrain parameters for radiation modeling from digital elevation data, IEEE Transact. Geosci. Remote Sens. 28 (1990) 963-969.

[57] R. Yokoyama, M. Shlrasawa, R.J. Pike, Visualizing topography by openness: A new application of image processing to digital elevation models, Photogramm. Eng. Remote Sens. 68 (2002) 257-265.
[58] M. Doneus, Openness as visualization technique for interpretative mapping of airborne Lidar derived digital terrain models, Remote Sens. 5 (2013) 6427-6442.

[59] J. Jasiewicz, T.F. Stepinski, Geomorphons - a pattern recognition approach to classification and mapping of landforms, Geomorphology 182 (2013) 147-156.

[60] E.R. Davies, Computer and machine vision: Theory, algorithms, practicalities, 4th Ed, Academic Press, 2012, pp. 871.

[61] J. Canny, A computational approach to edge detection, IEEE Trans. Pattern Anal. Mac. Intell. 8 (1986) 679-698.

[62] M. Carrero-Pazos, A. Vázquez-Martínez, B. Vilas-Estévez, As Trend: Towards a new method for the study of ancient carvings, J. Archaeol. Sci. Rep. 9 (2016) 105-119. 